Research Paper

\title{
Chemicals and lemon essential oil effect on Alicyclobacillus acidoterrestris viability
}

\author{
Maria Cristina Maldonado, Marina Paola Aban, Antonio Roberto Navarro \\ Instituto de Biotecnología, Facultad de Bioquímica, Química y Farmacia, \\ Universidad Nacional de Tucumán, Tucumán, Argentina.
}

Submitted: July 16, 2012; Approved: April 4, 2013.

\begin{abstract}
Alicyclobacillus acidoterrestris is considered to be one of the important target microorganisms in the quality control of acidic canned foods. There is an urgent need to develop a suitable method for inhibiting or controlling the germination and outgrowth of A.acidoterrestris in acidic drinks. The aim of this work was to evaluate the chemicals used in the lemon industry (sodium benzoate, potassium sorbate), and lemon essential oil as a natural compound, against a strain of A.acidoterrestris in MEB medium and in lemon juice concentrate. The results pointed out that sodium benzoate (500$1000-2000 \mathrm{ppm})$ and lemon essential oil (0.08- 0.12- $0.16 \%)$ completely inhibited the germination of A. acidoterrestris spores in MEB medium and LJC for 11 days. Potassium sorbate (600-1200 ppm) was more effective to inhibit the growth of the microbial target in lemon juice than in MEB medium. The effect of sodium benzoate, potassium sorbate and essential oil was sporostatic in MEB and LJC as they did not affect spore viability.
\end{abstract}

Key words: sodium benzoate, potassium sorbate, essential oils, Alicyclobacillus acidoterrestris.

\section{Introduction}

Alicyclobacillus acidoterrestris has been isolated from spoiled acidic juices and recognized as a spoilage microorganism (Cerny et al., 1984, McIntyre et. al. 1995, Splittstoesser et al., 1994); it is considered to be one of the important target microorganisms in the quality control of acidic canned foods. The spores of this bacterium can germinate and grow under high acid conditions $(\mathrm{pH}<4.5)$ (Baumgart et al., 1997, Yamazaki et al., 1996), and show a high capacity for survival due to their high heat resistance under the thermal treatments of acidic drinks currently in use (Maldonado et al., 2008, Murakami et al., 1998, Pontius et al., 1998). There is an urgent need for the related industries to develop a suitable method for inhibiting or controlling the germination and outgrowth of $A$. acidoterrestris in such products.

Chemicals, thermal treatments and organic acids have been used since the 1990s to inhibit A. acidoterretris spores (Hsiao and Siebert 1999, Shearer et al., 2000). The use of commercial disinfectants or ethanol was also studied in the past to achieve the same effect (Orr and Beuchat 2000). Nowadays, however, western countries are experi- encing a trend towards green consumerism in their quest for fewer synthetic additives and more environment friendly compounds (Burt, 2004).

Essential oils are aromatic oily liquids obtained from plant material; some 3000 essential oils are known, out of which about 300 are commercially important for their flavour or fragrance (Van der Braak and Leijten, 1999).

Bevilacqua et al. (2008) evaluated the use of cinnamaldehyde, eugenol and limonene to inhibit $A$. acidoterrestris and compared their effectiveness with that of a traditional chemical like sodium benzoate.

This study was aimed at evaluating the use of chemicals in the lemon industry (sodium benzoate, potassium sorbate) and lemon essential oil as growth inhibitors of $A$. acidoterrestris in culture media and LJC. Our work is the first research to study the effect of lemon essential oil against $A$. acidoterrestris.

\section{Materials and Methods}

\section{Microorganism}

The highly heat resistant $A$. acidoterrestris used in this work was supplied by CIATIac (Centro de Investi-

Send correspondence to M.C. Maldonado. Instituto de Biotecnología, Facultad de Bioquímica, Química y Farmacia, Ayacucho 465, Universidad Nacional de Tucumán. Tucumán, Argentina. E-mail: cristimaldone@hotmail.com. 
gación y Asistencia Técnica a la Industria) and it was kept in orange serum agar (OSA) (Murray et al., 2007) at $4{ }^{\circ} \mathrm{C}$. The strain was confirmed for biochemical tests (mobility, citrate assimilation, catalase and indol production) (Maldonado et al., 2008).

\section{Bacterial activation and spore production}

Cells were activated in different culture media to determine the best one for A.acidoterrestris growth. They were orange serum medium $(0 \mathrm{~S})(\mathrm{In} \mathrm{g} / \mathrm{L}$; tryptein: 10; dextrose: 4 ; yeast extract: $3 ; \mathrm{K}_{2} \mathrm{HPO}_{4}$ : 2.5 ; orange juice: $200 \mathrm{~mL} ; \mathrm{pH}$ 5.5), malt extract (MEB) (In g/L: malt extract: 17; peptone: 3 ; $\mathrm{pH}: 4.5$ ) and bacillus acidocaldarius medium (BAM) (In g/L: yeast extract: 5; peptone: 5; glucose: 5; $\mathrm{K}_{2} \mathrm{HPO}_{4}$ : 4; $\left.\mathrm{pH}: 4\right)$.

The microorganism was spread in the three media and incubated for $48 \mathrm{~h}$ at $44{ }^{\circ} \mathrm{C}$. At the end of this period the cells were transferred to a tube with sterile distilled water and Tween 80 until reaching an OD of 0.250 at $540 \mathrm{~nm}$, corresponding to $10^{6}$ spores $/ \mathrm{mL}$. They were kept at $6{ }^{\circ} \mathrm{C}$ for 7 days to stimulate sporulation. To destroy the vegetative cells, the spore suspension was shaked for $10 \mathrm{~min}$ at $80^{\circ} \mathrm{C}$. The spores thus obtained were used for the tests performed.

\section{Chemicals}

Sodium benzoate (500-1000-2000 ppm); potassium sorbate (600-1200 ppm) and lemon essential oil (LEO) (0.08 - $0.12-0.16 \%)$ were used at concentrations employed in the lemon industry. Stock solutions of sodium benzoate and potassium sorbate in water were freshly prepared before each use and sterilized by filtering through membranes (0.2 $\mu \mathrm{m}$ Millipore).

The lemon oil composition was (\%): $\alpha$ - pinene: 1.93; $\beta$ - pinene 12.26; D-limonene: 67.17; Geranial: 1.25; Sabinene: $2.14 ; \beta$ - Mircene: $1.55 ; \gamma$ - Terpinene:8.33; others: 5.37, determinated by HPLC.

The juices, chemicals and LEO were supplied by CITROMAX SACI.

\section{Antimicrobial assay}

$100 \mathrm{~mL}$ of MEB or lemon juice concentrate (LJC) + sodium benzoate (500-1000-2000 ppm) or potassium sorbate (600-1200 ppm) or LEO (0.08-0.12-0.16\%), were inoculated separately with $10^{6}$ spores $/ \mathrm{mL}$ of $A$. acidoterrestris.

The samples were then incubated at $44{ }^{\circ} \mathrm{C}, 250 \mathrm{rpm}$ for 11 days and the microbial growth was evaluated every day by measuring absorbance at $540 \mathrm{~nm}$ using a UV-visible Beckman DUS30 spectrophotometer.

Inoculated MEB or LJC without chemicals were used as control. To determine the surviving spores after antimicrobial assays, the samples of every day were spread onto the surface of MEA and incubated at $44{ }^{\circ} \mathrm{C}$ for $48 \mathrm{~h}$.

Growth data were expressed as Inhibition index evaluated as follows,

$$
\text { I. I. }=\frac{A c-A s}{A c} \times 100
$$

where Ac represents the absorbance of control sample and As the absorbance of the sample + active compound (Chaibi et al., 1997). All analyses were performed in triplicate.

\section{Results and Discussion}

MEB, OSA and BAM were the three media evaluated to determine their suitability to support the microorganism growth. MEB was the best for its higher sugar concentration and it was used for inhibition assays.

Sodium benzoate (500 - 1000 - $2000 \mathrm{ppm}$ ) inhibited completely the germination of $\mathrm{A}$. acidoterrestris spores (Figure 1). Bevilacqua et al. (2008) proposed Na-benzoate $(0.1-0.5 \mathrm{~g} / \mathrm{L})$ as an antimicrobial to inhibit $A$. acidoterrestris spores, because the acidic $\mathrm{pH}$ required by this microorganism could enhance the effectiveness of the compound. The effect of Na-benzoate was dose-dependent and sporostatic, as it did not affect spore viability.

Potassium sorbate was not effective in the spore germination control, because $600 \mathrm{ppm}$ of it inhibited growth for 2 days with a significant absorbance increase after 6 days of storage and population number at the end of the running time was lower, than that recorded in the control sample (Figure 2). A higher concentration of this compound (1200 ppm), however, prolonged the lag phase (time before the beginning of spore outgrowth) to 7 days.

In order to compare the effectiveness of the chemicals the inhibition index in MEB broth +500 or $600 \mathrm{ppm}$ of chemicals was evaluated. A. acidoterrestris was completely inhibited by sodium benzoate 500 ppm after 11 days (inhibition index 99\%), without affecting the germination of spores, whereas an inhibition index of approximately $30 \%$ was observed in MEB $+600 \mathrm{ppm}$ potassium sorbate after 11 days.

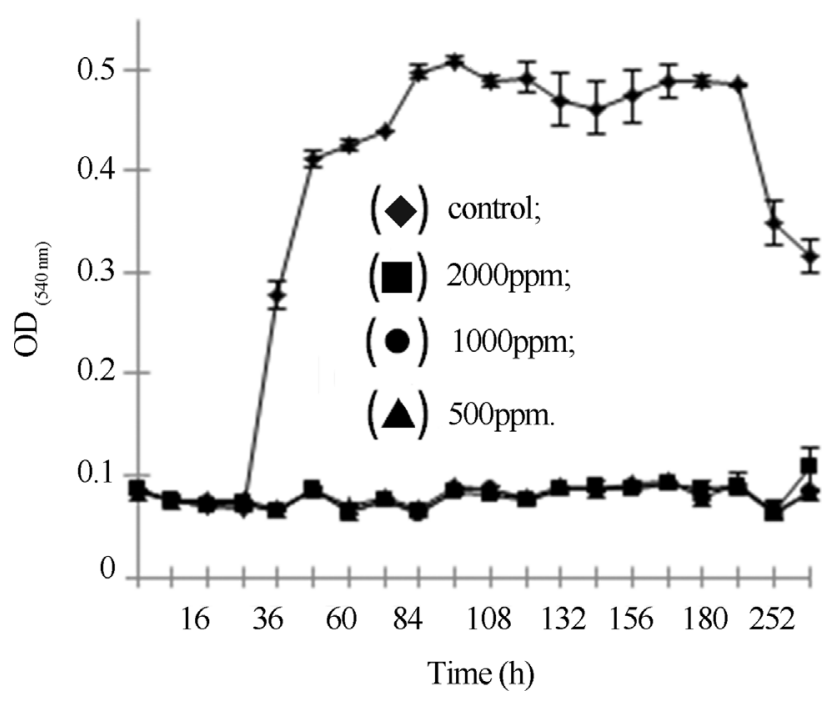

Figure 1 - Germination of $A$. acidoterrestris spores in $\mathrm{ME}+$ sodium benzoate. Data are accompanied by the standard deviation. 
LEO (0.08 - $0.12-0.16 \%)$ inhibited completely the germination of $A$. acidoterrestris spores within the running time (11 days) (Figure 3). The oil activity is related to the chemical structure, proportion and interaction of its components (Delaquis et al., 2002, Dorman and Deans 2000, Marino et al., 2001). LEO composition is quite variable, depending on the mode of extraction (enfleurage or distillation), plants and climate. This could explain the difference between our results and those of Bevilacqua et al. (2008), because they reported that active compounds of LEO (cinnamaldehyde, eugenol and limonene) were better than oils. However, limonene was not effective against $A$.

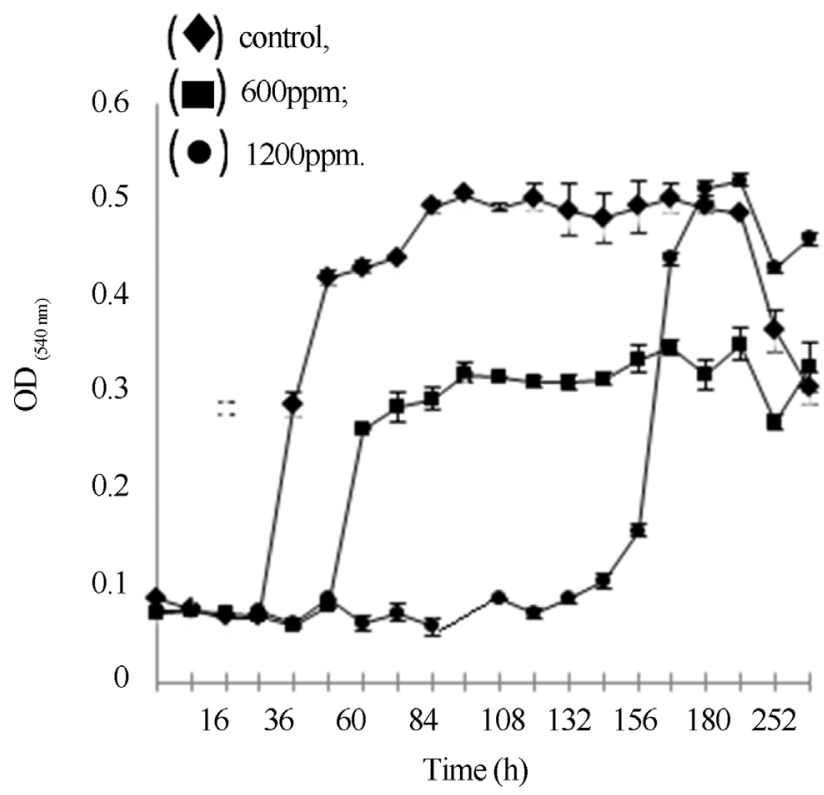

Figure 2 - Germination of A. acidoterrestris spores in $\mathrm{ME}+$ potassium sorbate. Data are accompanied by the standard deviation.

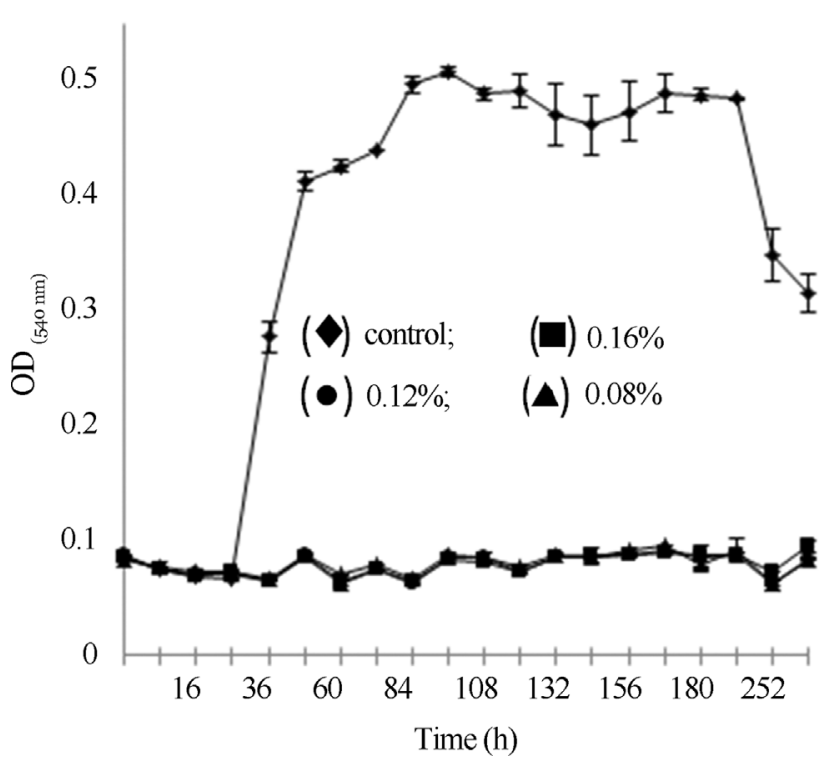

Figure 3 - Germination of A. acidoterrestris spores in ME + lemon essential oil. Data are accompanied by the standard deviation. acidoterrestris spores while cinnamaldehyde was the most effective compound.

Antimicrobial susceptibility could be strain dependent and probably related to the isolation source or to a different composition and/or distribution of fatty acids in the cytoplasmatic membrane. As suggested by Chaibi et al. (1997), differences between strains could be explained by a difference in their hydrophobic behavior. The more hydrophobic an organism is, the more sensitive it will be to hydrophobic antimicrobial agents, as the active compounds of LEO. These ideas, however, are only a speculation and need to be confirmed.

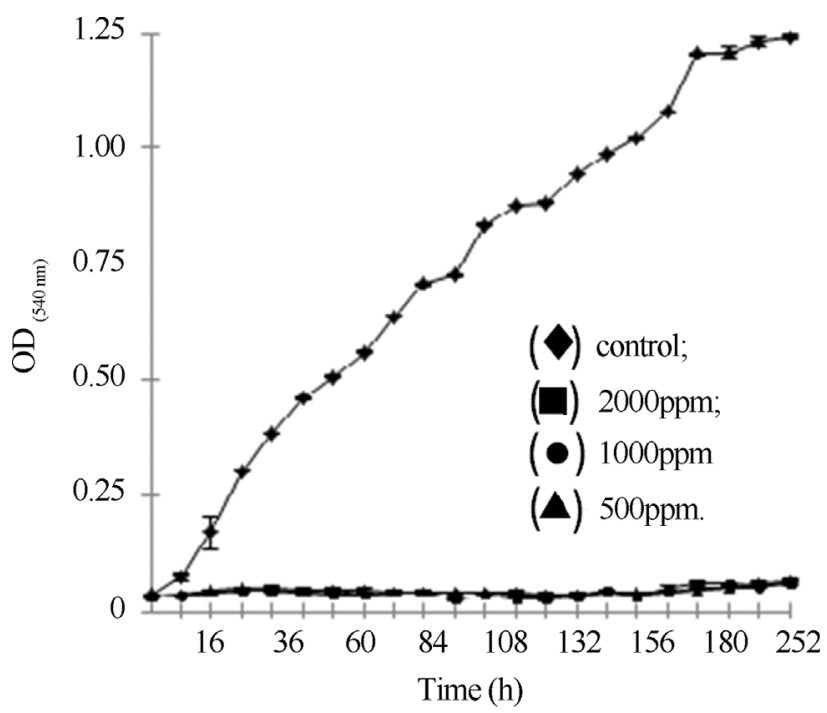

Figure 4 - Germination of $A$. acidoterrestris spores in concentrated lemon juice + sodium benzoate. Data are accompanied by the standard deviation.

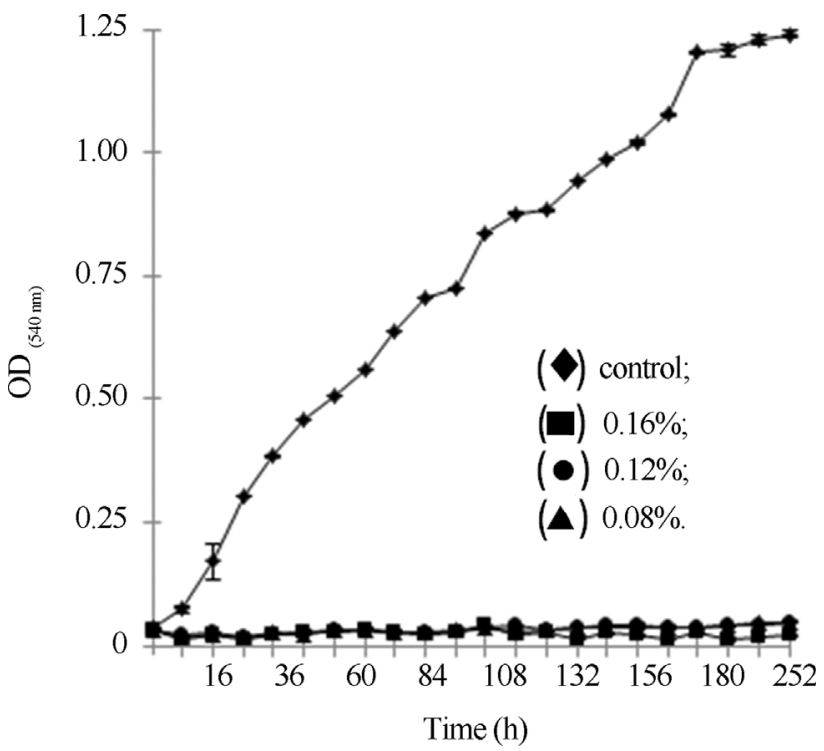

Figure 5 - Germination of $A$. acidoterrestris spores in concentrated lemon juice + lemon essential oil. Data are accompanied by the standard deviation. 
Microorganism growth in LJC was twice as high (OD $1.245 \mathrm{~nm}$ ) as in MEB medium (OD $0.505 \mathrm{~nm}$ ). The different chemical composition of MEB medium and LJC used for the assays could have a direct influence on $A$. acidoterrestris growth. The germination capacity of the microorganism in high acidity conditions, allows its growth in fruits juices and other foods with a $\mathrm{pH}$ lower than 4 (Terano et al., 2005).

Lemon juice + sodium benzoate or LEO in all the concentrations studied, inhibited A. acidoterrestris spore germination (Figures 4 and 5). The acidic $\mathrm{pH}$ of LJC could enhance the effectiveness of sodium benzoate because its antimicrobial activity rises when $\mathrm{pH}$ decreases (Batchelor 1984).

Potassium sorbate was more effective in LJC than in MEB medium because $A$. acidoterrestris growth was controlled, OD: 0.290 and $0.215 \mathrm{~nm}$ for 600 and $1200 \mathrm{ppm}$ respectively at the end of the running time (11 days) (Figure 6).

Walker and Phillips (2008) reported that sodium benzoate and potassium sorbate inhibited the germination of $10^{3}$ spores $/ \mathrm{mL}$ in apple juice; this difference could be attributed to the fact that our inoculums were $10^{6}$ spores $/ \mathrm{mL}$.

A study on the acid inhibition of spore germination proposed by Smoot and Pierson (1981), indicated that sorbate could act as a competitive inhibitor of some germinants, like L-alanine and L-cysteine; moreover, its effect seemed to be reversible, as spores germinated after putting them in a fresh medium.

In order to compare the effectiveness of the chemicals, the inhibition index in LJC +500 or 600 ppm of sodium benzoate or potassium sorbate was evaluated.

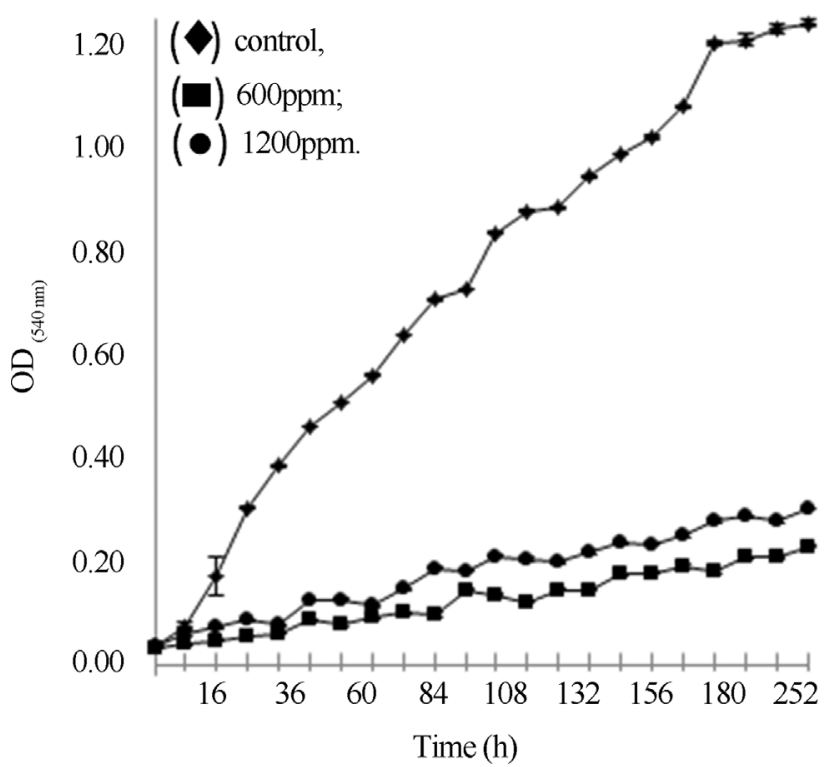

Figure 6 - Germination of $A$. acidoterrestris spores in concentrated lemon juice + potassium sorbate. Data are accompanied by the standard deviation.
A. acidoterrestis was completely inhibited by sodium benzoate 500 ppm after 11 days (inhibition index 99\%), without affecting the germination of spores, whereas an inhibition index of approximately $75 \%$ was observed in LJC $+600 \mathrm{ppm}$ potassium sorbate after 11 days. The effect of sodium benzoate, potassium sorbate and LEO was sporostatic in MEB and LJC as they did not affect spore viability.

The use of LEO could be considered an open approach, as juice stabilization could be achieved through some natural molecules, extracted from plants and fruits. Hence, the consumer should not consider these antimicrobials as chemicals, but as natural ingredients of juices; moreover, some of these compounds are usually added to commercial juices (eg. apple juice added with lemon extract) to improve product flavour.

The results of this work show that is possible to control the germination of $A$. acidoterrestis spores in MEB medium and LJC through the use of a natural compound like LEO because it inhibits bacterial spore outgrowth and cell multiplication without affecting germination ability. Accordingly, these results led us to conclude that LEO in lemon juice or its addition is a suitable application for preventing the spoilage caused by $A$. acidoterrestris in most acidic drinks.

\section{Acknowledgments}

We are grateful to María Antonieta Gordillo for technical assistance.

\section{References}

Batchelor V (1984) Further microbiology of soft drinks. In H. W. Houghton (Ed.), Developments in soft drinks technology-3. Essex, UK: Elsevier Applied Science Publishers Ltd.

Baumgart J, Husemann M, Schmidt C (1997) Alicyclobacillus acidoterrestris: occurrence, significance and detection in beverages and beverage bases. Fluessiges Obst 64:178-180.

Bevilacqua A, Corbo MR, Sinigaglia M (2008) Inhibition of Alicyclobacillus acidoterrestris spores by natural compounds. Int J Food Sci Technol 43:1271-1275.

Burt S (2004) Essential oils and their antibacterial properties and potential applications in food. A review Int J Food Microbiol 94:223-253.

Chaibi A, Ababouch LH, Belasri K, Boucetta S, Busta FF (1997) Inhibition of germination and vegetative growth of Bacillus cereus $\mathrm{T}$ and Clostridium botulinum $62 \mathrm{~A}$ spores by essential oils. Food Microbiol 14:161-174.

Cerny G, Hennlich W, Porolla K (1984) Spoilage of fruit juices by bacilli: isolation and characterization of the spoiling microorganisms. Zeitschrift für Lebensmittel-Untersuchung und -Forschung A, 179:224-227.

Delaquis PJ, Stanich K, Girard B, Mazza G (2002) Antimicrobial activity of individual and mixed fractions of dill, cilantro, coriander and eucalyptus essential oils. Int J Food Microbiol 74:101-109. 
Dorman HJD, Deans SG (2000) Antimicrobial agents from plants: antibacterial activity of plant volatile oils. J Appl Microbiol 88:308- 316 .

Hsiao CP, Siebert KJ (1999) Modeling the inhibitory effects of organic acids on bacteria. J Food Microbiol 47:189-201.

McIntyre S, Ikawa JY, Parkinson N, Haglund J, Lee J (1995) Characteristics of an acidophilic Bacillus strain isolated from shelf-stable juices. J Food Protect 58:319-321.

Maldonado MC, Belfiore C, Navarro AR (2008) Temperature, soluble solids ad $\mathrm{pH}$ effects on Alicyclobacillus acidoterrestris viability in lemon juice concentrate. J Ind Microbiol Biotechnol 35:141-144.

Marino M, Bersani C, Comi G (2001) Impedance measurements to study the antimicrobial activity of essential oils from Lamiacea and Compositae. Int J Food Microbiol 67:187195.

Murakami M, Tedzuka H, Yamasaki K (1998) Thermal resistence of Alicyclobacillus acidoterrestris spores in different buffers and pH. Food Microbiol 15:577-582.

Murray MB, Gurtler JB, Pyu JH, Harrison MA, Beuchat LR (2007) Evaluation of direct plating methods to enumerate Alicyclobacillus in beverages. Int $\mathrm{J}$ Food Microbiol 115:59-69.

Orr RV, Beuchat LR (2000) Efficacy of disinfectants in killing spores of Alicyclobacillus acodoterrestris and performance of media for supporting colony development by survivors. J Food Protect 63:1117-1122.
Pontius AJ, Rushing JE, Foegeding PM (1998) Heat resistance of Alicyclobacillus acidoterrestris spores affected by various $\mathrm{pH}$ values and organic acids. J Food Protect 61:41-46.

Shearer AEH, Dunne CP, Sikes A, Hoover DG (2000) Bacterial spore inhibition and inactivation in foods by pressure, chemical preservatives and mild heat. J Food Protect. 63:15031510.

Smoot L, Pierson M (1981) Mechanisms of sorbate inhibition of Bacillus cereus $\mathrm{T}$ and Clostridium botulinum 62A spores germination. Appl Environ Microbiol 42:477-483.

Splittstoesser DF, Churrey JJ, Lee CY (1994) Growth characteristics of aciduric sporeforming bacilli isolated from fruit juices. J Food Protect 57:1080-1083.

Terano H, Kaori T, Sakakibara Y (2005) Characterization of spore germination of a thermoacidophilic spore-forming bacterium, Alicyclobacillus acidoterrestris. Biosci Biotech Biochem 69:1217-1220.

Van de Braak SAAJ, Leijten GCJJ (1999) Essential oils and oleoresins: a survey in Netherlands and other major market in European Union. Pp. 116. Rotterdam, The Netherlands: CB1, Centre for the Promotion of Imports Developing countries.

Walker M, Phillips CA (2008) The effect of preservatives on Alicyclobaillus acidoterrestris and Propionibacterium cyclohexanicum in fruit juice. Food Control 19:974-981.

Yamazaki K, Teduka H, Shinano H (1996) Isolation and identification of Alicyclobacillus acidoterrestris from acidic beverages. Biosci Biotech Biochem 60:543-545.

All the content of the journal, except where otherwise noted, is licensed under a Creative Commons License CC BY-NC. 